\title{
INNOVATIVE TEACHER EDUCATION THROUGH PERSONALISED LEARNING: DESIGNING TEACHING AND LEARNING SCENARIOS
}

\author{
S. Alisauskiene ${ }^{1}$, L. Kaminskiene ${ }^{1}$, L. Milteniene ${ }^{1}$, R. Meliene ${ }^{1}$, A. Rutkiene ${ }^{1}$, A. \\ Kazlauskiene $^{2}$, A. Siriakoviene ${ }^{2}$, S. Kontrimiene ${ }^{3}$, V. Venslovaite ${ }^{3}$, C. O'Mahony ${ }^{4}$, \\ L. Lee ${ }^{4}$, H. Guðjónsdóttir ${ }^{5}$, J.V. Kristinsdóttir ${ }^{5}$, A.K. Wozniczka ${ }^{5}$ \\ ${ }^{1}$ Vytautas Magnus University (LITHUANIA) \\ ${ }^{2}$ Siauliai University (LITHUANIA) \\ ${ }^{3}$ Vilnius University (LITHUANIA) \\ ${ }^{4}$ University College Cork (IRELAND) \\ ${ }^{5}$ University of Iceland (ICELAND)
}

\begin{abstract}
The growing diversity of the student population twinned with a shift towards more learner-centred education provides the impetus to develop innovative teaching approaches. Imagined as personalised learning (PL), this approach argues for greater flexibility for the learner and more opportunities to include students' voice in the design and enactment of learning. This paper distils the learning from the members of the INTERPEARL project consortium including Lithuanian Universities Siauliai University (SU), Vytautas Magnus University (VMU), and Vilnius University (VU) together with their international partners University of Iceland (UI), and University College Cork, Ireland (UCC). The paper is based on the theoretical assumptions of social construction and takes mixed method approach to uncover the learning from implementing a personalised learning process to encourage greater learner agency and co-creation of learning. This paper will introduce the $\mathrm{PL}$ framework developed by the INTERPEARL consortium and two related concepts, namely Learning Scenarios and Learning Design. The learning from the implementation of the PL Framework in Iceland, Ireland, and Lithuanian is uncovered, with a methodology of self-study of teaching and teacher education practices (S-STEP), and student-teachers surveys providing a strong rationale for more PL approach.
\end{abstract}

Keywords: Personalised learning, innovative teacher education, teaching and learning scenarios.

\section{INTRODUCTION}

Nowadays, the demographic profile of students in schools is more complex than ever before, and increasing cultural, linguistic and developmental diversity of classrooms, along with the pressure to achieve high academic standards for everybody has significant implications for how classroom teachers should be prepared to meet these demands [8]. Promoting inclusivity through and within education as well as teacher education systems remains a persistent challenge and a necessary imperative for the 21st century [3]. At the international level, changes in the system of education are closely related to the shift of educational paradigms with the clear focus on the learner on both school student, teacher student, and practicing teacher as a learner. In this context, the PL is important because it is impelling learning from a traditional teaching practice to a model that can meet every students' learning needs. PL is an umbrella term under which many practices fit, each designed to accelerate student learning by tailoring instruction to individuals' needs and skills. PL must expand to allow students opportunities to explore and develop their own passions and interests. PL moves away from teachers being imparters of knowledge, to showing students how to learn, creating the curiosity and thirst for what to do with knowledge [17]. Personalized teaching and learning guides the whole education system to the learner and changes in his/her role, moving from "the user" to the collaborating partner and creating the unique learning path. PL involves the student into the in-depth learning process, enables to acquire learning experience, and ensures better learning outcomes [14]; [1]. PL refers to "the use of multiple instructional modes to scaffold each student's learning and enhance the student's motivation to learn and metacognitive, social, and emotional competencies to foster self-direction and achieve mastery of knowledge and skills" [21]. Through personalised instruction, the teacher is attuned to each student's evolving personal competencies and differentiates learning assignments accordingly [21, p.13]. In its nature, the PL is collaborative; it isn't teacher directed or student directed, it is both [10]. It raises student engagement due to students feeling ownership and pride in their learning [17]. In this context, two concepts intersect: the learning scenario 
(LS) and the learning design (LD), which encourage students to take responsibility for their own learning and achievements [7]. Mentioned above assumptions are taking into consideration while implementing the international strategic partnership in higher education-based project "Innovative teacher education through personalized learning". The authors of the paper aim to share with learning from the implementation of the PL framework, illustrative practice-based examples of its enactment with a view to encouraging greater learner agency and co-creation of learning.

\section{THEORETICAL FRAMEWORK}

The paper is based on the theoretical assumptions of social constructivism and employs mixed method approach to distil key learning and practice based examples that foster greater learner agency and co-creation of learning while focussing on the PL. We emphasize social construction of learning as a social cultural process that occurs in the context of human relationships and activity in teacher education. The sociocultural context affects how we learn through participation. Learning process is constituted by the context of which it is a part [11]. Despite the often agreed upon premise that all learning should be personalised and relevant, shifting traditional, time-based systems and instructional practices to be in alignment with a PL model is difficult work that few institutions have successfully approached. Transforming a school system, a learning system, into an organization that places PL at the core is very complex and multi-faceted work [22]. What's needed, therefore, is deep and systemic change in the ways we organize instruction. If we can change the relationship between time and learning, so that time becomes the variable and learning the constant, then educators will be much better able to help students take greater responsibility for and ownership of their own learning [5].

This paper focuses on the following main concepts related to the personalized learning: the learning scenario (LS), and the learning design (LD). In this section of the paper, we describe the main phases $\&$ attributes that ground the implementation of PL through LS and LD. Within the framework for adopting PL, we base our understanding on six main phases of learning personalization process [4]. During the first step, teachers identify the learners' profiles based on their needs, strengths, challenges, aptitudes, interests, talents, and aspirations. The students' profiles enable teachers to recognize their preferences for accessing the content and its form, for effective engagement strategies and for models to express their knowledge and understanding. During the second step, the teacher set diverse learning zones, based on students' profiles. This way every student can freely choose his preferred physical or virtual learning zone. The third step includes the development of universally designed lesson, or flexible blueprint for creating instructional goals, methods, materials, and assessments that work for everyone. The fourth step involves driving and supporting questions, encouraging students to take part in instruction co-design activities. The fifth step aims to select tools, resources, and strategies for appropriate learning and teaching. The final step includes an assessment as learning, or actively engaging learners to reflect and critically assess their learning progress. In addition, PL is a progressively student-driven model of education that empowers students to pursue aspirations, investigate problems, design solutions, chase curiosities, and performances.

The continuum of PL moves from teacher-driven approach to a more student-driven approach with the four main attributes of PL in the canter: voice, social construction, co-creation, and self-discovery [12]. The first defining attribute is voice of learners. In a PL culture, each member is seen as a respected and valued participant. Student's involvement and engagement in "the what" and "the how" of learning in the learning process is of most importance in PL. Instead of being passengers on the curricular journey that the teachers have mapped out, students are valued participants, helping to set the curricular agenda. Student empowerment comes from an environment in which students recognize the power of their own ideas and recognize the shift that can happen by being exposed to others' ideas [12]. Regular student participation and engagement in co-creating performances constitutes an opportunity to flex their innovative and creative ideas. Social construction meaning that students build ideas through relationships with others as they theorize and investigate in pursuit of common learning goals as people learn through dialogue, discussion, building on one another's ideas [12]. There is real power in feeling that you are not alone, in the sense of camaraderie that comes from working collaboratively to effect a change, create a performance, or build a prototype. For students, the experience of individual bits of knowledge, ideas, and actions coalescing into a larger and better whole can be transformative, even magical [12]. Social construction occurs as students seek out information, ideas, and perspectives to guide task development by consulting experts or peers who have intimate knowledge of the topic. Students also share the results of their work to guide others, illustrate thinking, and offer own ideas. Educators and community members see the value of collaboration as we move forward in this journey [12]. Co-creation is an invitational act. Students are invited to co-create a 
personalised plan using "backward design" principles. In PL, students work with the teacher to develop a challenge, problem, or idea; to clarify learning goals; to envision what is important to present for the assessment; and to outline an action plan that will result in an outcome that achieves the desired results (learning actions). Through the regular co-creation students build their innovative and creative ideas [12]. Self-discovery is a process of students' coming to understand themselves as learners. They reflect on the development of ideas, skills, knowledge, and performances. This helps them envision what might come next as well as what they might do, explore, and create next. Students develop the capacity to articulate areas of strength and concern and view this as a proactive opportunity to grow. It leads to become self-directed learners who know how to manage themselves in a variety of situations [12].

\subsection{Scenario-based personalized learning}

Scenario-based learning (SBL) is one method that can be used face-to-face as well as in online learning in order to engage students and move beyond passive presentation of content [11]. Learning scenario represents a pedagogical method for developing a set of activities and their sequence learning paths, enabling students to acquire skills and knowledge. More specifically, LS defines the main activities, roles, learning structure and environment context - location, resources, tools, and services. LS defines both the role of the students and what they have to accomplish as a set of learning activities in order to attain the expected learning outcomes [2]. SBL is based on the principles of situated learning theory, which argues that learning best takes place in the context in which it is going to be used, and situated cognition, the idea that knowledge is best acquired and more fully understood when situated within its context. SBL uses interactive scenarios to support active learning strategies such as problem-based or case-based learning. In the process, students must apply their subject knowledge, critical thinking and problem solving skills in a safe, real-world context. SBL supports the constructivist view of education that learning takes places when students are able to construct meaning from experiences and activate prior knowledge [11]; [15]. SBL is often non-linear, and can provide numerous feedback opportunities to students, based on the decisions they make at each stage in the process. SBL may be self-contained, in that completing the scenario is the entire task, or it may be the first part of a larger assignment requiring first completion of the scenario, and then a written or oral reflection and self-assessment on the process. How to start creating SBL?

- Identify the learning outcomes: It is important to identify what it is you want students to achieve on completion of the scenario, and then to work backwards from the learning outcomes to create the situation that will lead to this learning.

- Decide on the format: Is scenario going to be delivered in the face-to-face or online environments? What media (photographs, video etc.) and other resources will you need? If you are using an online scenario, will you provide other supporting activities, such, discussion forums, etc.?

- Choosing a topic: Non-routine tasks lend themselves to scenario-based learning. Consider using 'critical incidents' and challenging situations that have occurred in your subject area.

- Identify the trigger event or situation: This will be the starting point of your scenario. As you create the scenario, identify decision points and key areas for feedback and student reflection.

- Peer review your scenario: Ask colleagues to work through the scenario to ensure that it flows in the way you expect, and achieves the outcomes you intended.

While applying SBL there are some issues to clarify: Are the outcomes based on skills development or problem solving? Is it difficult or even unsafe to provide real-world experience of the skills? Do your students already have some relevant knowledge to aid decision-making? Do you have time and resources to design, develop, and test an SBL approach? Will the content and skills remain relevant for long enough to justify the development of SBL? [6].

\subsection{Learning design and Universal Design for Learning}

Learning Design (LD) is the framework that supports learning experiences. It refers to deliberate choices about what, when, where and how to teach. Decisions need to be made about the content, structure, timing, pedagogical strategies, sequence of learning activities, and the type and frequency of assessment in the course, as well as the nature of technology used to support learning. Universal Design for Learning (UDL) is a powerful framework for the design and enactment of learning is focussed on ensuring greater flexibility in teaching to support diverse learners. UDL supports the 
redesign of curricula and assessments to challenge and engage a diverse range of students. The UDL framework was developed from neuroscience research [19], which challenges the idea of an "average" learner and describes three main networks in the brain relating to the "why", the "what", and the "how" of learning. The affective network considers how to stimulate motivation and sustain enthusiasm amongst students and aligns well with the emphasis on co-creation and inclusion of student voice in the INTERPEARL PL framework. The recognition network considers how to ensure a varied approach in how information and content is presented. The strategic network considers how to ensure a range of options for students to demonstrate their understanding, which aligns well with the INTERPEARL PL framework in terms of the provision of 'choice' for students. Through the UDL framework, educators can design assessments, methods and materials that are inclusive of a range of learners while also considering how to support students to develop a professional identity and insight within the discipline or area of practice. UDL begins with a focus on the learner - who they are, what they know, how they think, and how to reach them effectively so they get the most out of their educational experience. It shifts the focus of education from simply delivering content to moulding the full instructor-learner experience. PL is interpreted and enactment in many diverse ways in education. Sometimes it's used in the context of educational technology tools that offer lessons keyed to the academic level of individual students. Other times it refers to the personal touch of a teacher getting to know a student, learning about their interests and tailoring lessons to meet their needs and interests. $\mathrm{PL}$ implies increased learner choice and the provision of multiple pathways to learning and many ways to demonstrate competency, and resists the notion that all students learn the same way [20].

\section{METHODOLOGY}

This paper reflects the mixed method approach carried out in two different sites and draws on a range of data collection methods. The first study provides a baseline for the implementation of teaching approaches focussed on enacting elements of the INTERPEARL PL framework [1]. The second is the self-study of teacher education practices, whereby teacher educators study their own practice of changing the teaching approaches within their teacher education institutions. As a research methodology, self-study is a frame for practitioners to critically reflect on their practice. It gives them a forum to understand what they do, how and why they do it, and how to improve and find a way to make the study public. It requires evidence for reframed thinking and transformed practice, which are derived from an evaluation of the impact of developmental efforts while interacting with colleagues, students, the educational literature and previous work. In addition, the researcher gains an ontological sense for her stance in the professional world and a space for dialogue about knowledge and understanding of her own practice [13]; [18].

The aim of the paper is to introduce the personalised learning framework developed by the INTERPEARL consortium and two related concepts, namely Learning Scenarios and Learning Design, and to share with learning experiences gained from the implementation of the personalised learning framework in Iceland, Ireland, and Lithuania.

The participants of this research were us - authors of this paper who work as teacher educators and students who experienced teaching and learning scenarios, which we present in this paper.

Data sources and collection. Data sources for the Icelandic study included examples of teaching and learning scenarios, reflective journals, students' projects and TOCs (Tickets out of the classroom, used to gather information on the learning that has happen over the day, as explained in [13]. Icelandic data were collected in the fall semester of 2020.

Another data collection method was survey. Lithuanian project partners developed the questionnaire of the survey that includes the following questions: What teaching methods and strategies do you use? Which methods and strategies work? What challenges do you face in teaching your subject(s)? What is the role of students in planning and improving the study subject and assessing the study results? How do you inform students what they will need to be able to do after completing the subject you are teaching? Does the student contribute to the review and reconstruction of the study subject results and content and how? What are the possibilities for the student to choose his/her own pace, time and forms of assessment? How does the student assess his/her study results? How do you, as a teacher, find out about the study results achieved/not achieved by students? How do you decide that you need to update and improve your study subject? Why are you reviewing topics, methods, tasks? How do you respond to students' suggestions for subject improvement? Please share successful and unsuccessful teaching experiences. The questions for student teachers and teacher educators are similar. 
A student survey was conducted in Spring 2020 with the UCC student teachers, who were engaging in a Professional Master of Education. The survey participants were student teachers engaging in the tutorials, which function as a space to support critical reflection and discussion concerning practice based elements of teaching. In addition, a teacher educator survey was conducted in three Lithuanian Universities (as mentioned in the Abstract) in Spring 2020. The survey data were collected using the method of an online survey. A link to the survey was sent by e-mail to teachers working in the selected teacher education programs and to students studying in the same programs. The questionnaire was placed in a virtual environment and the answers were submitted online.

Data analysis. The INTERPEARL PL framework was used to create a coding frame to analyse the responses to the open-ended questions in the teacher educator survey in SU and the student survey conducted in UCC. This approach ensured the alignment with the existing baseline data regarding students' evaluation of the pedagogical approaches utilised in the tutorials, which comprise part of their Professional Master of Education course. In the analysis of data collected in Iceland, the focus was on the learning processes of students and teacher educators. Anna began by writing narratives from the class, Jónína and Hafdís read the narratives and dotted down critical or interesting points and questions, then the research team used reflective meetings to analyse the data. By performing these tasks couple of times, spiral analysis was conducted. The process consisted of questioning the data, framing and reframing of individual and team's interpretations of the data and revisiting the data [23].

Ethical considerations. In case of Iceland, an informed consent from all students participating in the course described in the narrative was obtained, and data was collected in line with the regulations of The Icelandic Data Protection Authority. Ethics was submitted in Ireland to the Social Research Ethics Committee in University College Cork for a survey of students. In case of Lithuania, the voluntary participation in the survey was ensured.

\section{RESULTS}

\subsection{Iceland}

Our narrative (Anna, Hafdís and Jónína Vala) provides insight into experiences of applying a teaching and learning scenario called Using multicultural lenses to develop learning for all. The scenario comes from a course: Working in inclusive practices taught at a graduate level. The overall goal of the course is that students gain awareness of importance of being critical and reflexive towards self and teaching practice/environment/material used. The course is co-taught by a team of five teacher educators, including Hafdís and Anna. Anna developed the teaching and learning scenario, and the three of us analysed and reflected on it. Due to COVID-19 the 2-hour class was carried out in a virtual setting and Anna and students were in separate places (home, workplace, etc.). Various digital technologies and tools, including Zoom, AnswerGarden, Youtube, Canvas and Padlet were applied.

\subsubsection{Preparation of the class}

Before the class, Anna framed its aim - to explore with students the idea of using multicultural lenses and purpose - to create a learning space for all students to reflect on, understand better and transform their own attitudes and practice. To build up students' curiosity toward the topic of the class, Anna used two hooks. Firstly, she asked the students to read the chapter Multicultural education as transformative education [24]. Secondly, students were asked to bring to the class one of the following: a book or material that they use in their teaching/practice, a book that they or members of their family read, a toy, a photo from school, a school handbook or a job description. Anna did not reveal the exact purpose of bringing the material. In her journal, she wrote: "I wanted to attract students' interest, but also ensure that she applies the ideas of UDL by allowing a space for freedom of personalised, meaningful, real-life and challenging learning opportunities."

This class took place in the first month of the semester, when the team of teacher educators and the students were still getting to know each other and building up trust. Anna reflected in her journal: "I was aware that the task and freedom of choice may be difficult for some students to cope with. I also wondered whether they would be prepared for the class at all". However, building on teams' and own experience from teaching this particular course and on the students' reflections from previous classes, Anna was excited and optimistic about the upcoming class. 


\title{
4.1.2 Creating a learning space for all
}

In the beginning of the class, all of the students and Anna were together. Anna summarised the chapter and then opened up space for students to share reflections on the main concepts: transformation of self and transformation of teaching/practice, and why the two were crucial for teachers, who work with diverse group of students. Anna then focused particularly on the first concept, i.e. transformation of self and the students were asked to think about the questions that the author posed in the chapter, i.e.: Who am I? What are the cultural threads that make up the fabric of who I am today? What privileges have allowed me to be where I am today? What privileges have helped who I am, what I think and how I teach? Anna encouraged them to share their thoughts with the group and noted down in her journal: "I wanted the students to start to reflect on their identity, beliefs and attitudes. I wanted them to see and make links between self, practice and theory and to experience their transformation." Anna asked students to brainstorm and write in the link to a word cloud provided the first word that came to students' minds when thinking of Africa. After giving students a few minutes to submit their answers, the word cloud was ready. The most frequent words on the word cloud were: poverty, desert, heat, water shortage, far away, straw huts and wild animals. As Anna read the story "How to write about Africa" students studied the word cloud, she also encouraged them to watch a TED talk: "The danger of a single story". In our reflective meeting, Anna said:

I did not realise how much impact this small task would have on the students. I was shocked, but so were they - suddenly our eyes opened and we became aware of our own prejudices as we had a concrete example in front of us. We could not escape talking about it, but I felt that this was a safe space for all of us to work with the feelings that this experience brought (Anna's journal, fall 2020.

This task helped to build more trust between Anna and the students, and the students themselves.

\subsubsection{Personalising learning}

To continue working with the experience from the task Anna presented the idea of using multicultural lenses in real situations by showing examples from abroad - about examining multicultural picture books for the ECEC and from Icelandic context - about gender equality project in a preschool in Reykjavík. She wrote:

\begin{abstract}
I thought that it was important to calm students down by helping them realise that their experiences were not unusual. By showing students real-life examples from different contexts, I wanted to reassure them that this class was a learning space where everyone is welcome to be sincere and open about their feelings (Anna's journal, fall 2020).
\end{abstract}

Next, Anna discussed the assignment with students. It was divided into three phases - first two took place during the class, while the last one, a written reflection was to be submitted by the students after the class. In the first phase of the assignment, the students worked individually for 10 minutes. They investigated their material with multicultural lenses, bearing in mind earlier discussion and reading material. Anna provided supportive questions [23] for the students to have in mind as their critically examined and reflected on their material, each student on their own. The questions included: e.g., Who has the power in this story/image/material? How is language used to create images of people of a particular group? Who has written the story? Whose voices are heard and whose are missing? What does the chosen material say about race, class, culture, gender, age? In the second phase of the assignment, the students were sent randomly to breakout rooms of three-four where they had 20 minutes to exchange their first thoughts and reflections on the material they brought to the class. They were encouraged to continue using the supportive questions provided in that phase.

\subsubsection{Reflecting on the teaching and learning process}

At the end of the class, all students came back to the main room and they shared their thoughts on both the material, but also on the feelings that accompanied them while they explored the material with the multicultural lenses. At the end of the class, the students wrote anonymous TOCs (Tickets Out of the Classroom). They were asked to answer two questions: What are you going to take away from this class? What would you like to learn next? One of the students wrote:

Good class... interesting topic that encourages critical thinking while working with the material we use in everyday practice... I work in a preschool and I could immediately spot many interesting issues concerning my "favourite book" that I haven't thought of before... (TOC, fall 2020). 
Another student claimed that he "became more aware of the roots of his culture and willing to transform his thinking". The students had a week to finalise the third phase of the assignment, a written reflection on: three factors they noticed in the material, but have not previously thought more of; two factors that could be transformed in relation to the material so that it responds to the needs of diverse students, but the transformation requires more time and work; one factor that can be transformed immediately and without much investment. A math teacher who examined her teaching material revealed:

The second thing I examined was the statements. There are some based on stereotypes: boy is taller than a girl, boy buys "boyish things" in a sports shop (other things were certainly available), boy is in love with a girl and vice versa, girls jump rope, girls do jam, boys cut trees, girls own pets, a boy buys a snowmobile (excerpt, fall 2020).

Another student who works as a coach wrote:

I am not a teacher and have not taught so much...so I chose a book with rules in my discipline: I noticed that all the pictures in the book are of men referees. It is interesting to see that there are no pictures of women, especially in the light of the emphasis on increasing the share of women referees in this discipline. It is very easy to change this because it's an online book... I also see that the members of the committee responsible for publication of the book are all men, it explains a lot of things (excerpt, fall 2020).

Anna read teacher students' assignments and provided formative assessment, e.g. by asking additional questions for reflection. As she explained later while discussing the class with Hafdís and Jónína Vala: "I did not grade the assignments. I consider them rather as an evidence to determine students' learning progress and an opportunity to point them towards their next steps". She used formative assessment to help students in validating their learning and its eventual application as students reflect on and transform their practice.

\subsection{Ireland}

The Irish team conducted a survey with students participating in tutorial groups that comprise the Professional Master in Education. The survey tool was developed by colleagues in Lithuania and drew on the emerging PL Framework. The tool was implemented by the partners in the project with some minor adaptations to local context. It comprised o8 questions and used an open text box per question to enable students to provide a detailed response. Engagement in the survey was voluntary and student consent was sought in advance. The central aim of the survey was to gather student feedback on their experience of the tutorial. Of a potential 27 students, 18 responded to the survey.

\subsubsection{Context of the study}

The Professional Master of Education (PME) in UCC is a 2 year, full-time, level 9 postgraduate initial teacher education course designed to qualify graduates as post-primary teachers. It combines 2 yearlong school placements with university lectures and tutorials, to develop student teachers' requisite professional knowledge, skills, understanding and competences. Students are encouraged to integrate educational theory and practice through extensive reflection on their own professional classroom practice. They are supported in their development by experienced teachers in schools and tutored by specialist School of Education staff in nurturing their professional identity as teachers. The $30 \mathrm{ECT}$ credit School Placement module runs over two semesters in both years of the programme (ED6330 in PME1 and ED6360 in PME2) and includes 24 hours of tutorials with assigned tutors to scaffold and support teacher development and school placement experience. It was agreed by the UCC partners on the INTERPEARL project that the tutorial would be the site for implementing aspects of the Personalized Learning Framework [1]. The PME tutorial is focussed on supporting individual students to bridge the teaching and theory divide and provides a space for discussion, reflection and peer feedback on personal experiences of classroom-based scenarios.

\subsubsection{Survey findings}

The principal pedagogical approaches identified by students in the PME tutorials are collaboration, discussion and modelling. The survey respondents indicated group discussion and problem solving in the tutorial as being most supportive of their school placement but also highlighted the sharing of resources and ideas with their peers. The respondents did not identify specific challenges to learning in the tutorial apart from two respondents who highlighted time constraints as limiting time for speaking or for addressing issues related to their teaching practice. While reflecting on their engagement with 
the tutor, the survey respondents highlighted the positive atmosphere in the tutorial and how this fostered cooperation and open discussion amongst the students. They noted that the tutors encouraged respectful and professional exchanges in the space and facilitated the discussion through use of questioning and turn-taking. In response to a question on students' involvement in the coconstruction of the content or outcomes of the tutorials, survey respondents indicated that the tutorials encouraged student voice and choice. They shared that students in the tutorial suggest which topics to be focussed on in the session and they can inform the focus of future tutorials. The respondents also highlighted that students share resources with their peers. Survey respondents indicated that there is a considerable amount of self-evaluation evident in the tutorial. Students are encouraged in the tutorial to reflect on and develop their practice. Peer evaluation is also included in the tutorial as students engage in microteaching workshop and gather specific feedback from peers on their practice. When considering how best to enhance their learning in the tutorials, the majority of survey respondents ( 3 , $\mathrm{n}=11$ ) indicated that nothing was required. Two respondents highlighted that increased provision of classroom scenarios and resources would be helpful. One respondent proposed that students take a greater lead in teaching the class. Another survey respondent suggested setting out success criteria and key expectations at an early stage in the tutorial. The final survey question asked respondents to share any significant successful or unsuccessful learning experiences in the tutorial. Of the 15 respondents, five of the respondents mentioned microteaching as successful, four highlighted discussion and peer exchange, and two indicated the positive feedback and encouragement in the tutorial as ensuring a successful learning experience. One respondent felt microteaching was unsuccessful due to their expressed discomfort in commenting on peers' teaching. Individual respondents mentioned "mapping our paths as teachers"; "successful completion of placement"; "reflection"; "open discussion"; "sharing ideas and resources", "reflection"; "Advice on managing difficult students" and "Special Educational Needs management strategies" as being successful.

\subsection{Lithuania}

In Lithuania, 20 teacher educators from SU VMU, \& VU took part in the survey in Spring 2020. The selection of participants was targeted. Only those teachers who are involved in the update of their teaching subjects in line with the concept of PL were invited to answer the questions. The method of content analysis was chosen to analyse the data by combining the methods of value analysis and qualitative content analysis. During open-label coding, the transcribed study data were divided into individual parts according to meanings. This made it possible to single out the data units that reveal the tendencies typical of study objects. The original concepts given to the latter data units are called "labels", which consist of participants' statements (phrases), and are given "in vivo codes".

\subsubsection{Survey findings}

The survey shows that teacher educators emphasizes their main role of student involvement into planning the study outcomes and creation of the opportunities of the student self-assessment in the study process. Teachers agree with the role of the student as a decision-making partner in planning and improving the study subject content and outcomes, but at the same time, they see the student as an episodic partner in establishing agreements. When naming the student's role, as an episodic partner in establishing agreements, teachers emphasise their role more often at the beginning: "At the beginning of the course we discuss with students their expectations and the structure of the subject". At the end of the course, some changes were admitted: "Students' reflection at the end of the course allows identifying more or less relevant topics, teaching and learning methods that students think are the most appropriate"; "Usually students express their opinion about the study of the subject at the end of the semester ...". As the involvement of students in planning and improvement of the study subject increases, the role of the student changes, i.e. transitions from an episodic partner to an independent decision-maker. Survey shows that teachers rarely assign students the role of an independent decision-maker. In certain cases, conditions are created for the learner to choose the topics, methods and ways of assessment. Our findings also suggest that the conditions created by teachers for consolidating students' roles manifest themselves in various ways: clarifying students' expectations, building experience, listening to their opinions and suggestions as well as creating conditions for reflection, discussion and assessment.

Summing up, we would like to stress that the INTERPEARL PL framework synthesises key learning theories, recognises the interconnectedness of the learner and teacher journey and suggests practical steps in learning design to implement a personalised learning approach in the classroom (see [1] for full details of the framework). The survey tool used in this study reflects aspects of the PL framework, and a coding frame based on the PL framework has been used to analyse the responses to the open- 
ended questions in the survey. The survey tool included elements of the PL framework in referring to teacher-student collaborations and the co-creation of learning \& self-evaluation, thereby seeking to uncover specific evidence of the inclusion student voice and choice in the learning experience. The survey tool has some limitations as this pre-framing of the questions potentially influences the responses by directing attention to particular pedagogical practices. The questions in the survey could have been broken into separate questions \& it is difficult to interpret why a student may neglect to answer three sub-questions of one question, for example. These design issues can be offset by facilitating in-class discussion based on more explicit sharing of the PL framework \& considering how its elements are, or are not, evident in the tutorial, as well as considering the potential transfer of the framework to professional practice and the design and enactment of learning in students' classrooms.

\section{CONCLUSION}

Scenario-based learning in eLearning uses real-life situations to validate the learning comprehension and more significantly its eventual application. It offers a highly interactive and immersive approach that can be used effectively by organizations to check-point learner's knowledge and check if learners will be able to apply the learning on their job. From a learner's perspective, it provides problem solving environment that is relatable (as it depicts real life situations), safe mode to practice, and understand the impact and consequences of their decisions and choices. Several design approaches to craft scenario- based learning can be used. It can be used to check the comprehension as well as application across most of the corporate training needs. Design scenarios can be developed at two levels: 1) Mini or basic scenario-based learning is used to validate learner's recall and basic comprehension (good for basic problem solving); 2) Complex or branching scenario- based learning is used to validate learner's proficiency to apply the learning. A flexible instructional approach can be used within traditional eLearning course at suitable junctures (such as "Pause and Reflect" or in a Check Understanding assessment). Alternatively, you can drive the entire course through a narrative master scenario / story with a cast of characters and have a combination of scenarios within the learning path. Student survey data provides a strong rationale for the approach proposed in the personalised learning framework that seeks to accentuate choice and voice.

\section{ACKNOWLEDGEMENTS}

The authors acknowledge the participation of members of the Professional Master of Education programme in University College Cork, namely: Dr Tracey Connolly, Dr Domnall Fleming, Dr Jacinta McKeon, and Dr Stephen O'Brien.

\section{REFERENCES}

[1] S. Alisauskiene, H. Guðjónsdóttir, J.V. Kristinsdóttir, T. Connolly, C. O'Mahony, L. Lee, L. Milteniene, R. Meliene, L. Kaminskiene, A. Rutkiene, V. Venslovaite, S. Kontrimiene, A. Kazlauskiene, and A.K. Wozniczka, UNESCO, Personalized Learning within Teacher Education: A Framework and Guidelines, 2020. Retrieved from https://unesdoc.unesco.org/ark:/48223/ pf0000374043?fbclid=IwAR0H9a6pvp340bGLBVeB_h8kDUnX65ij7IZOK8MeU7IQnk5RsD3v2P6j P_I

[2] A. Antonova, B. Bontchev, Designing Scenarios for Personalized Learning: Enabling Teachers to Apply Educational Video Games in Class. International Journal of Education and Learning Systems. Volume 4, 2019. Retrieved from: http://iaras.org/iaras/journals/ijels

[3] A. F. Ball, C. A. Tyson, "Preparing Teachers for Diversity in the Twenty-first Century", Studying Diversity in Teacher Education. Lanham, Maryland: Rowman and Littlefield, 2011.

[4] B. Bray, K. McClaskey, A Step-by-Step Guide to Personalize Learning. Learning \& Leading with Technology, 40(7), 2013, pp. 12-19.

[5] J. J. Cirasuolo, Backtalk: A call for systemic change for personalized learning. Phi Delta Kappan, 100 (8), 80, 2019. Retrieved from: A call for systemic change for personalized learning kappanonline.org

[6] R. Clark, Accelerating expertise with scenario based learning. Learning Blueprint. Merrifield, VA: American Society for Teaching and Development, 2009. 
[7] C. Deakin, C. Goldspink, M. Foster, "Telling identities: Learning as script or design?" Learning emergency discussion paper, 2013. Retrieved from: http://learningemergence.net/events/lasi-dlawkshp

[8] L. Florian, N., Pantić, Erratum: Teacher Education for the Changing Demographics of Schooling. In: Florian L., Pantić N. (eds) Teacher Education for the Changing Demographics of Schooling. Inclusive Learning and Educational Equity, vol 2. Springer, Cham, 2017. https://doi.org/10.1007/978-3-319-54389-5_17

[9] J. P. Gee, Social linguistics and literacies: Ideology in discourses (3rd ed.). New York: Routledge, 2008.

[10] R. Hipkins, Different ways of thinking about learning. New Zealand Council for Educational Research. NZCER: Ministry of Education, 2014. Retrieved from: http://www.nzcer.org.nz/research/publications/different-ways-thinking-about-learning

[11] K. Iverson, \& D. Colkey, Scenario-based e-learning design. Performance Improvement, 43(1), 1622, 2004. Retrieved from ERIC database.

[12] B. Kallick, A. Zmuda, Student at the Center: Personalized Learning and Habits of Mind, ASCD, Alexandria, Virginia, USA, 2017.

[13] J.V. Kristinsdóttir, S.R. Jónsdóttir, K.R. Gísladóttir, E. Óskarsdóttir, and H. Guðjónsdóttir, (2019) "Cultivating Self-Study," in 2nd International Handbook of Self-Study of Teaching and Teacher Education. Springer International Handbooks of Education. (J. Kitchen, A. Berry, H. Guðjónsdóttir, S. Bullock, M. Taylor \& A. Crowe, eds), pp. 1419-1437, Singapore: Springer, 2019. https://doi.org/10.1007/978-981-13-1710-1_49-1

[14] C. Leadbeater, We think: Mass innovation, not mass production, London, UK: Profile, 2009.

[15] Y. Mery, R. Blakiston, 26th Annual Conference on Distance Teaching \& Learning, 2010. Retrieved from: http://www.uwex.edu/disted/conference

[16] J. Mendoza and D. Reese, "Examining multicultural picture books for the early childhood classroom: Possibilities and pitfalls," Early Childhood Research \& Practice, vol. 3, no. 2, pp.2-32, 2001.

[17] OECD, Schooling Redesigned: Towards Innovative Learning Systems. Paris: OECD Publishing. 2015, doi:10.1787/9789264245914-en

[18] S. Pinnegar and M. L. Hamilton, Self-study of practice as a genre of qualitative research: Theory, methodology and practice. Dordrecht: Springer, 2010

[19] D.H. Rose and A. Meyer, Teaching every student in the digital age: Universal Design for Learning. Alexandria, VA: ASCD, 2002.

[20] K. Schwartz, Step by Step: Designing Personalized Learning Experiences For Students, 2014. Retrieved from: Step by Step: Designing Personalized Learning Experiences For Students | KQED)

[21] S. Redding, S. Through the student's eyes: A perspective on personalized learning. Philadelphia, PA: Temple University, Center on Innovations in Learning, 2013.

[22] T. Rooney, Beyond reform: Systemic shifts towards personalized learning, Superintendent, Lindsay Unified School District 2016. Retrieved from: Beyond reform: Systemic shifts towards personalized learning (pearsoned.com)

[23] A.P. Samaras Self-Study Teacher Research: Improving Your Practice through Collaborative Inquiry. Los Angeles/CA: SAGE Publications, 2011.

[24] M. Souto-Manning, Multicultural Teaching in the Early Childhood Classroom. New York/NY: Teachers College Press, 2013. 